\title{
ATTITUDE TO MATHEMATICS, STUDY HABIT AND ACADEMIC PERFORMANCE OF SELECTED SECONDARY SCHOOLS IN MAKURDI METROPOLIS
}

\author{
Prof. D. C. Musa ${ }^{1 *}$, Adamu Garba ${ }^{2}$ \\ ${ }^{* 1,2}$ Department of Science Technology and Mathematics Education, Nasarawa State University, Keffi, Nasarawa State \\ *Corresponding Author: -
}

\begin{abstract}
: -
This study examined the attitude to Mathematics, study Habit and Academic Performance of selected Secondary Schools in Makurdi. The study was anchored on theory of confluent education. The researcher used survey research design was adopted for study while the census sampling technique was utilized to determine the respondents for data analysis. A sample of 202 respondents obtained by the use of a structured questionnaire from two secondary schools in Makurdi Metropolis. The data collected were analyzed using multiple linear regression analysis. The probability value of the estimate was used in testing the hypotheses of the study. The result of the regression analysis indicates that study attitude has a positive effect on Student Attitude (STA) and Student Performance (PEF) and the relationship is statistically significant $(p<0.05)$ and in line with a priori expectation. This means that a unit increases in on Student Attitude (STA) will result to a corresponding increase in the Student Performance (PEF) by margin of 20.8\%. Study habit (STH) was negatively related to Student Performance in selected Secondary Schools in Makurdi Metropolis (PEF) and the relationship is not statistically significant ( $p>0.05)$. It was concluded that that student attitude has a significant effect on students' performance and academic achievement in the selected secondary schools in Makurdi Metropolis. It was recommended among others that school administrators, teachers' and parents, should work collaboratively hand-in-hand to maximize students' performance by helping to improve their study habit and attitude towards school. They should see to it that every needed material, resources, varied activities, and differentiated instruction are available and applied in order to cater for students' need to learn and be motivated enough.
\end{abstract}

Keywords: Attitude, Study, Habit, Academic, Performance, Benue, Nigeria.

\section{(a) $(\$)$}




\section{INTRODUCTION}

Mathematics is the oldest of all sciences that have developed through the ages having a direct impact on the quality of human life on our planet. It is unanimously agreed that mathematics is the language of science and technology and also in some other disciplines like art and culture, holding the key to development and progress of the country as well as humanity as whole. The mathematics is a backbone of students to achieve and develop the skill in reasoning and thinking level. In elementary stage the base on mathematics should be imposed to develop mental observation and creativity or innovativeness (Oyedeji, 2016).

Due to the lack of proper knowledge on mathematics the student suffer in all spheres of life. There is a general consensus among educators that mathematics is an important and useful subject for development in every country. It is the key to technology. Despite its importance and influence, it is a subject most feared by students of the primary school and secondary school levels. So from the grass root level the teaching of mathematics should be effective and scientific.

The study of mathematics should aid individuals in ordering, organizing and investigating their environment hence its knowledge should be made to attain more generality of the people (Ohuche, 1988). Students' performance in mathematics varies across different nations due to the difference in the adopted teaching strategy as well as students study habits. Some students' get disgusted with methods that render them inactive in the learning process as well as fancy text backs that have not much for students' selection of exercises, activity and less engendering towards a richer understanding of the subject matter. Studies revealed that major contextual influences such as students' environment, family and historical and cultural contexts influence their learning (Acido, 2010).

The study habits of students could be positive and yielding high level of cognition while their negative attitudes can be distorting, repulsive and consequently lead to poor performance; as well as affecting the impact on students' acquisition of reasoning skills. Acido (2010) confirms an obvious observation that students' interest in things that he or she needs to learn determines his or her acquisition of certain skills or abilities. Indicators of good study habit among students' are organized notes, lessons and materials, having a regular time and place for studying lessons, making decisions about priorities concerning time and goals, good parental models and personal responsibility over what one does or does not do (Acido, 2010; Charnley, 2006).

In order to improve students attitude and study habit, Mackeracher (1996) suggested the use of learning partnerships group discussions and case studies for students to maintain a consistent pattern of learning behavior. Lock (1981) opined that learners should improve on their personal developments skills, process skills and expression skills. Personal development skills denotes personal discipline and good management skills while the process skills are the methods and techniques students adapt when studying which incorporates reflective thinking process. However, students' performance in Mathematics has been on a decline over the years Study attitude is usually used to refer to a student's positive attitude toward the specific act of studying and the student's acceptance and approval of the broader goals of a college education. Study habits typically denotes the degree to which the student engages in regular acts of studying that are characterized by appropriate studying routines (e.g., reviews of material) occurring in an environment that is conducive to studying. Our investment in higher education is enormous. We are painfully reminded of this whenever seemingly qualified students fail in college or drop out from graduate school. What explain these performance discrepancies? To protect this investment, researchers have focused on understanding the academic success and failure of students and have examined a wide array of student characteristics as determinants of academic performance. These individual difference factors can be coarsely subdivided into intellective (cognitive) and non-intellective (non-cognitive) factors. Psychology and education have a good grasp on the intellective factors that encompass most of the variables typically considered in the admissions process, such as scores on cognitively loaded admissions tests. Recent meta-analytic evidence has shown that a consideration of these intellective factors is valuable given the substantial predictive validities of students' prior grades and the ubiquitous predictive power of admissions tests at both the college and graduate school levels across a range of outcome variables (Bridgeman, McCamley-Jenkins, \& Ervin, 2000).

There would appear to be general agreement amongst teachers that study habits and attitudes are likely to exert considerable influence on the academic performance of their students, and it is regarded as axiomatic that 'good' study habits will secure 'good' scholastic results. This is true at all levels of education, but more especially in secondary and tertiary education where so much emphasis is placed upon academic achievement as shown by examination successes. Before attempting to consider what elements are likely to contribute to good study habits, it would seem important to have a clear conception of what is meant by the term 'study'. There is a tendency on the part of teachers to treat the words 'study' and 'learning' as synonymous, and while this is excusable on account of the close affinity which exists between these terms, yet there is a distinction and this must be made.

Research on the correlation between study habit and students academic performance has for long received attention from scholars and educational agencies. For instance, Ansari (1994) conducted a study to find out the relationship between study habits and academic performance of the students. Findings of the study revealed a positive correlation between study habit and academic achievement. Similarly, Nneji (2002) conducted a series of studies to find out the relationship between academic success and study habit and reported positive relationship between the two variables. Study habits are learning tendencies that enable students to work privately. Azikiwe (1998) describes the study habit as the adopted way 
and manner a student plans his private readings, after classroom learning so as to attain mastery of the subject. According to her, good study habits are good assets to learners because they (habits) assist students to attain mastery in areas of specialization and consequent excellent performance, while opposite constitute constraints to learning and achievement leading to failure. Good (1998) defines the term study habits as the students' way of study whether systematic, efficient or inefficient. Going by this definition, it literally means that good study habit produces positive academic performance while inefficient study habit leads to academic failure.

In effect, many students get low performance in certain subjects such as Mathematics. Accordingly, the ratio of low performing students in Mathematics to the total population of students is an essential factor of Mathematics education quality. Most notably, in terms of mathematics instruction, it seems that it is tough for the learners to cope up with the subject matter because of the students learning attitudes. Commonly, the students' mindset in Mathematics is very negative towards the subject. Even if teachers nowadays are very approachable and friendly, but most of the students hate numbers. This attitude worsens from time to time and in every year. Considering these observations, there is a need for quality education in the field of Mathematics of the teachers' that would help them to arouse students' self-confidence, interest, and attitude for an interactive class discussion. So, it is very vital that teachers need to determine the students' attitudes in engaging and learning Mathematics. This would serve as a blueprint in helping every student learned the subject.

\section{Statement of Problem}

It has been noted that individual differences in attitude to Mathematics and study habits adopted by students have affected mastery of subject areas in education as revealed by students performances over the years (Mark and Howard, 2009). A credit in Mathematics is required for students' entry into professional courses such as Engineering, Science, Medicine, Education and Economics but recently the performance of students in Mathematics was quite low. If this trend continues, students' pursuit for higher education will be hampered. The extent to which a student excels or performs in his or her studies depends on the kind of study habits he or she develops and uses to a very large extent. A student who develops and utilizes good study habits is likely to perform better in his studies when compared with the one who has bad study habits. Thus, study habit is very instrumental to the academic success of every student at all levels. However, one wonders the extent to which students in recent times develop and use their study habits; as most of the students in secondary school hardly know how to study. This position is further stressed by Mark and Howard (2009), who are of the opinion that the most common challenge to the success of students in all ramifications is lack of effective or positive (good) study habits. Most students do not have study plan to guide their studies. Some hardly attend classes, do their homework and prepare for their exams etc. This may not be unconnected to the recent abysmal performance of students in both internal and external exams.

\section{Objectives of the Study}

The main objective of this study is to examine how attitude to Mathematics, Study Habit affect Academic Performance in selected Secondary Schools in Makurdi Metropolis. The specific objectives of the study are to;

i. Examine the effect of student attitude to Mathematics on the performance of selected secondary schools in Makurdi metropolis and

ii. Determine the effect of study habit of Mathematics on the Performance in selected Secondary Schools in Makurdi Metropolis.

\section{Hypotheses of the study}

It is hypothesized that:

H01: Student attitude to Mathematics has no significant effect on the performance in selected secondary schools in Makurdi Metropolis.

H02: Study habit of Mathematics has no significant effect on the performance in selected secondary schools in Makurdi Metropolis

\subsection{LITERATURE REVIEW Conceptual Framework Concept of Study Habit}

How a student takes his or her studies, greatly determines his/her level of academic achievements. The level of preparation and learning strategies developed and employed consciously by students, go a long way to influence their level of academic performance. Thus, study habit and attitude are of the greatest students or learning factors that hugely influences students' academic achievements. If undermined by students at all levels, teachers, administrators, parents and guardians, school counselors and the government, then, the trend and menace of students' abysmal performance in both internal and external examinations would continue to boom and become more devastating and alarming.

Mark and Howard (2009) are of the opinion that the most common challenge to the success of students in all ramifications is a lack of effective or positive (good) study habit. They further maintain that if students can develop a good study habit and with good discipline, they are bound to perform remarkably well in their academic pursuit. Marc (2011) explains that students with learning problems, however, may still have generally inefficient and ineffective study habits and skills. Becoming aware of your learning habits or styles will help students to improve their performance.

Husain (2000) stresses that lack of effective or positive (good) study habits is a critical study problem among students at 
all levels. Grace (2013) also maintains that the process of learning is still a little mysterious but studies do show that the most effective process for studying involves highly active behavior over a period of time. In other words, to study effectively, one must read, draw, compare, memorize and test himself over time. The concept of study habit according to Husain (2000) is broad, as it combines nearly all other sub-concepts such as study attitude, study methods and study skills. Attitude is a mental and natural state of readiness, organized through experience, exerting a direct influence on the individual's response to all objects and situations with which is related. Attitude towards study has great contribution on academic achievement, and good study pattern. Successful learners adopt positive attitude towards study, and do not waste time or energy over what they have to do. If the learning experience is pleasant, the learner's attitude and motivation is usually positive, and if the learning experience is not pleasant he tends to avoid it.

Different students have different and unique study habits. What may be a good study habit to a particular student may be a bad one indeed to another student. As such, it is often difficult to practically pin-point that this is good and that is bad. In the opinion of Katelyn (2013), there is no doubt that different people study in different ways and it is a near certainty that what works for one person may not work for another. John (2010) opines that not all students are alike. There are several key study habits that are crucial to all students' success. One of such is study in a good environment, a little bit of background music, such as classical with no lyrics are fine and a good studying location. Whether studying in rain or shine, day or night, what is most important is to be consistent and stay on one schedule.

Generally, study habits can be classified into two-good study habits, and bad study habits. Good study habits according to Katelyn (2013) are sometimes referred to as positive or productive study habits. As the name implies, they are those pleasant study habits which have the tendency to improve the academic performance of students or that seem to produce good results. They are the study habits which make students successful in their studies after developing and applying them throughout their academic career. Good study habits occur as a result of practice and knowing what methods are most effective for you as a student.

When studying, stay away from distractions, such as the computer. Instead of procrastinating, work on a long term assignment daily, instead of studying the night before, study a little each night. Review what you learned in class every day when you get home, before starting homework. Also, a good tip is to review what you did in class the previous day at the beginning of class when you have a few minutes before the teacher starts talking. By learning the ways that you learn the best, you will be successful in your studies.

Katelyn (2013) therefore, identifies fourteen positive or good study habits which students can employ in order to improve their academic performance. They are: attending all classes, reviewing your notes daily, reading material prior to it being covered in class, study daily, have at least one conference with the professor, develop and learn a word list for the course, read materials to improve your background in the course (other than text), attend help session, attend learning resource lab when available, develop a list of possible questions, ask questions in class, study an old exam (when available), avoid a last minute cram session, and sleep at least 8 hours the night before exams commence. In the same vein, Harper and Row (2009), highlight good study habits as thus:

1. Studying every day Creating a quiet place at home or anywhere to study

2. Turning off the phone, TV and other devices that may disturb you when studying

3. Listening to soft music or white noise

4. Studying in a way that suits your learning style

5. Taking regular breaks

6. Studying early (do not wait for last minutes)

7. Studying the hardest things first, spending more time on topics you find difficult

8. Asking for help if one is struggling with his studies, taking notes as one study as well as organizing notes in a notebook or folder.

On the other hand, bad study habits according to John (2010) are negative or non- productive study habits which are undesirable and counter-productive to students' academic performance. When developed and utilized by students at all levels, they tend to hamper academic progress and performance of the users. Due to the peculiarity and uniqueness of individual student, what may be considered as bad study habits to student "A", may seem to be very productive and efficient for student "B". However, bad study habits generally range from procrastination, truancy, not taking note, selective reading, studying while watching television or what is generally regarded as distractive study etc. Nikki (2013) identifies bad reading habits to include studying with friends, listening to loud music, studying in uncomfortable conditions, cramming, etc. There are several factors that tend to affect students study habits. Anything can affect students' study habits. Their ability to study and concentrate can be increased by finding a quiet place where they can concentrate. Distractions such as phones, chat rooms, text messaging, TV, video games, music and computers can all decrease students' ability to learn. Whatever is going on around and within a student's own mind is going to affect his study habits (Nikki, 2013).

\section{Concept of Students Attitude}

Negative attitude towards study sometimes finds expression in comment such as "I study but cannot remember what I study" or "the lessons are too long". Attitude serves as index on how we think and feel about people, objects and issues 
in our environment.

Study attitude, according to Husain (2000), refers to the predispositions which students have developed towards private readings through a period of time. According to him, study attitude offers great possibilities for successful achievement in studies. Study method is the knowledge and application of effective study skills or techniques by students. Several study methods have been identified several effective study methods and skills that could be used by students based on the learning environment (Husain, 2000). Kelli (2009) posits that for students to succeed in their studies, they must be able to appropriately assimilate course content, digest it, reflect on it and be able to articulate the information in written and/or oral form.

What is fundamental is the ability of a student to acquire effective study habits and maintain a positive attitude. Many students feel that the hours of study are the most important. However, students can study for hours on end and retain very little. The more appropriate question is how students should study more effectively. Developing good time management skills is very important. Students must realize that there is a time to be in class, a time for study, time for family, time to socialize and time to just be alone. This is the right attitude for study. The critical issue is recognition that there must be an appropriate balance. Students should also have vision. A clearly articulated picture of the future they intend to create for themselves is very important and contributes to students' success in school. This will promote apassion for what they wish to do. Passion is critical and leads to an intense interest, dedication and commitment to achieving career goals and objectives (Sorensen, 2006).

Nexus between Attitude and Study Habit A great deal of research literature provides evidence that study habits and study attitudes are both significant variables which determine the academic performance of students (Awang, and Sinnadurai, 2010, Crede and Kuncel, 2008, Hussain, 2006, Ogunyemi \& Hassan, 2011). Yet, in spite of the perceived importance of study habits and study attitudes to educational achievement, very little attention was given by academic institutions to improve these factors. This is manifested from the very low understanding level and the equally poor and deteriorating knowledge of many students which is still a great concern of educators, parents and governments (Riaz, Kiran and Malik, 2002).

This problem is pointed out by Hurlburt, et.al (1991) as contextual and systemic: it is rooted in the educational process shared by students and schools. Consequently, the need to improve student's study habits and attitudes is deemed necessary to improve student's academic performance. Accordingly, it is essential for schools to determine factors which affect these characteristics adversely, propose remedial measures and employ strategies for the development of good study habits and study attitudes.

This is further supported by Hurlburt, et.al. (1991) from their study which suggested that a confluent educational philosophy (systemic and holistic) and using confluent educational strategies (through which students' social- emotional and personal empowerment needs are met) may enhance the school experience, improve study habits and attitudes, and ameliorate the high dropout rate among the students. The premise that improving study habits and attitudes will lead to academic success. It aimed to provide comparison data on the study habits and attitudes of the high achievers and underachievers and consider the implications of these findings in designing academic intervention programs. This will lead to the identification of negative study habits of students which may affect their educational achievement.

Understanding these negative characteristics will help lay the foundation of developing academic intervention programs as implications of confluent educational strategies that will help develop good study habits and study attitudes among the students (Riaz, Kiran and Malik, 2002). Very few studies have compared the study orientation (study habits and attitudes) possessed by different groups of college students, such as those with high GPAs versus low GPAs.

The study of Proctor, et. al. (2006) signified the importance of this line of research for several reasons. They pointed out that identifying characteristics that differentiate among groups of students would be helpful to know in which areas certain groups of students are likely to require remediation. In addition, acknowledging all of the variables that differentiate between high- and low- performing students furthers theoretical understanding of why some students succeed in college while others fail. Accordingly, this expanded understanding of all the factors that contribute to college success (and failure). This is important for the purposes of prediction (e.g., of who is likely to succeed in college) (Ogunyemi \& Hassan, 2011), identification (e.g., of students in need of intervention), and remediation (e.g., of skills that can be improved and have been linked to academic success.

\section{Theoretical framework Theory of confluent education}

The theory of confluent education is a vital consideration in determining strategies to improve student's study habits and study attitudes. Confluent education as described by Hackbarth (1997) is the type of learning intended to produce a sense of wholeness in people and society. Literature suggests that, as cited in the study of Hurlburt, et.al. (1991), confluent education holds promise as an educational philosophy that can address issues of identity, self-worth, interpersonal relationships, and societal pressures. The said authors describes this as systemic in orientation, meaning, students should not be regarded as objects to be molded into predetermined forms; rather students and teachers should work together to achieve a mutually empowering learning experience. This implies that students should be educated as a whole person in all aspects which includes his intrapersonal, interpersonal, and societal development. Moreover, literature suggests that, 
as cited in the study of Crede and Kuncel (2008), study habits and study attitudes are multidimensional in nature (Gettinger $\&$ Seibert, 2002). This means that effective studying requires not only that the students possess knowledge of appropriate studying techniques and practices (study skills), but also sustained and deliberate effort (study motivation), selfregulation, ability to concentrate, self-monitoring (study habits), and sense of responsibility for and value in one's own learning (study attitude).

\section{Empirical Review}

Ranjana and Kumar (2012) examined the Influence of Attitude towards Mathematics and Study Habit on the Achievement in Mathematics at the secondary stage. A sample of 500 students of Standard IX from Secondary School of South Kamrup District, Assam, participated in the present study, in which the relationship among the achievement in mathematics was most closely related with attitude towards mathematics and study habit. Analysis of data indicated that there was no significant difference on achievement in mathematics of the students in case of medium and sex. The regression equation thus obtained shows that attitude towards mathematics; study habit contributes $15.2 \%$, and $29 \%$ respectively to the Achievement in mathematics.

Charles-Ogan and Alamina (2014) examined Differential Students' Study Habit and Performance in Mathematics. The study adopted a descriptive survey using the Students' Study Habit Assessment Scale (SSHAS) instrument. A sample of 400 SSII Students randomly selected from a population of about 2,108 students in 16 public secondary schools in Port Harcourt Local Government Area were used. The instruments' reliability coefficient was 0.86, calculated using the Pearson Product Moment Correlation (PPMC) formula. The stated research questions were discussed using mean. Hypothesis was tested at 0.05 significant levels using t-test and ranked order correlation coefficient (Spearman rho). Findings of the study revealed that students' do have preference to specific study habits while studying mathematics. Students with high level of concentration, when devoted more time to problem solving had high performance irrespective of gender. There are no significant differences between students' study habits and their performance in mathematics. Based on these findings, it is recommended that mathematics teachers should adopt a wide range of instructional strategies in the teaching of mathematics at the senior secondary school level. Appropriate workshops and in-service training for mathematics teacher should be organized periodically, by the state government.

Jones and Ruch (1928) and Crawford (1929) also conducted investigations into the relationship between study time and academic performance. Their findings were based upon a study timetable covering the period of 1 week, and their results were low. Between them, these investigators found correlations between 0.04 and 0.11 . It would seem evident that high correlations emerged only when students were asked to assess the amount of time they spent in study over an extensive period of about a year Cooper and Foy (1969) examined the study time spent by the students in their sample. They reported that some students claimed to spend 16 hours a week in private study in addition to their 27 hours of lectures and practical courses, yet when the results of a sessional examination were compared with the amount of time spent by the students in study, there was found to be no correlation. They further discovered that long hours of study undertaken at the weekend did not necessarily affect examination performance in any way. On the other hand, they found that the examination scores of a group of weak students correlated negatively with the amount of study time at the weekend. They concluded, however, that in general it was the weaker students who tended to spend longer hours in private study than did the better students, and this conclusion was also supported by Fisher and Cotsonas (1965) who stated that weaker students worked harder than brighter ones judging from the amount of time they devoted to study.

Kelli (2009) posits that for students to succeed in their studies, they must be able to appropriately assimilate course content, digest it, reflect on it and be able to articulate the information in written and/or oral form. What is fundamental is the ability of a student to acquire effective study habits. Many students feel that the hours of study are the most important. However, students can study for hours on end and retain very little. The more appropriate a question is, determines how students should study more effectively. Developing goodtime management skills is very important. Students must realize that there is a time to be in class, a time for study, time for family, time to socialize and time to just be alone. The critical issue is recognition that there must be an appropriate balance. Students should also have vision. A clearly articulated picture of the future they intend to create for themselves is very important and contributes to students' success in school. This will promote a passion for what they wish to do. Passion is critical and leads to an intense interest, dedication and commitment to achieving career goals and objectives.

Marc (2011) explains that students with learning problems, however, may still have generally inefficient and ineffective study habits and skills. Becoming aware of your learning habits or styles will help students to understand why they sometimes get frustrated with common study methods. He observes that good study habits are essential to educational success; as they contribute to a successful academic future. Good study habits lead to good grades while good grades lead to admissions to better colleges and universities, possibly with a scholarship thrown in. This in turn, will lead to a great career. Developing good study habits to Marc is very crucial for every student irrespective of his level of education. It boosts students' ability to be self-disciplined, self-directed and ultimately successful in their degree programs.

\subsection{RESEARCH METHODOLOGY}

This study used a survey research design. Survey research designs are procedures in quantitative research in which investigators administer a survey to a sample or to the entire population of people to describe the attitudes, opinions, behaviors, or characteristics of the population. The population of the study is two secondary schools in Makurdi Metropolis 
purposively chosen from both private and public secondary schools. They are made up of senior secondary school students of Government Model Secondary school Makurdi with a population of one hundred twenty eight (128) students and Goodness Secondary School with a population of seventy four (74) senior secondary school students. This brings the population to two hundred and two (202) respondents used for the study. Since the population is of manageable size, the whole population of the study is used as the sample size. Thus, the census sampling technique was utilized to determine the respondents for data analysis. The data for the study was collected using questionnaire, coded and analyzed using computer-based Statistical Package for Social Sciences (SPSS version 20.0 for Microsoft Windows). The validity and the reliability of the instrument was established using the factor analysis. It was established that the instrument is valid and reliable as the validity score that considered Kaiser-Meyer-Olkin (KMO) and Bartlett's Test of Sphericity is above the threshold and the Cronbach Alpha Coefficient for reliability is above 0.7.

Table 1: Kaiser-Meyer-Olkin and Bartlett's test

\begin{tabular}{|c|c|}
\hline $\begin{array}{ll}\text { Kaiser-Meyer-Olkin Measure of Sampling Adequacy. } \\
\begin{array}{ll}\text { Bartlett's Test of } & \text { Approx. Chi-Square } \\
\text { Sphericity } & \text { Sig. }\end{array} \\
\end{array}$ & $\begin{array}{r}.932 \\
1.947 \\
3 \\
.005\end{array}$ \\
\hline
\end{tabular}

Source: SPSS Result, 2019

A pilot test was conducted. The input variable factors used for this study were subjected to exploratory factor analysis to investigate whether the constructs as described in the literature fits the factors derived from the factor analysis. From Table 1, factor analysis indicates that the KMO (Kaiser-Meyer-Olkin) measure for the study's three independent variable items is 0.932 with Barlett's Test of Sphericity (BTS) value to be 3 at a level of significance $\mathrm{p}=0.005$. Our KMO result in this analysis surpasses the threshold value of 0.50 as recommended by Hair, Anderson, Tatham, and Black (1995). Therefore, we are confident that our sample and data are adequate for this study.

Table 2: Reliability Statistics

\begin{tabular}{|r|l|l|}
\hline Cronbach's Alpha & $\begin{array}{l}\text { lbach's Alpha Based on } \\
\text { Standardized Items }\end{array}$ & N of Items \\
\hline .854 & .902 & 3 \\
\hline
\end{tabular}

Source: SPSS Result, 2019

As shown by the individual Cronbach Alpha Coefficient the entire construct above falls within an acceptable range for a reliable research instrument of 0.70 . The Cronbach Alpha for the individual variables is 0.854 and is found to be above the limit of acceptable degree of reliability for research instrument.

Table 3: Item-Total Statistics

\begin{tabular}{|l|r|r|l|r|r|}
\hline & $\begin{array}{c}\text { scale Mean if } \\
\text { Item Deleted }\end{array}$ & $\begin{array}{c}\text { Scale } \\
\text { Variance if } \\
\text { Item Deleted }\end{array}$ & $\begin{array}{l}\text { Corrected } \\
\text { Item-Total } \\
\text { Correlation }\end{array}$ & $\begin{array}{l}\text { Squared } \\
\text { Multiple } \\
\text { Correlation }\end{array}$ & $\begin{array}{l}\text { ronbach's Alpha if } \\
\text { Item Deleted }\end{array}$ \\
\hline PEF & 68.6000 & 236.884 & .522 & .533 & .766 \\
STA & 51.7000 & 124.642 & .410 & .959 & .825 \\
STH & 68.8000 & 161.958 & .714 & .606 & .749 \\
\hline
\end{tabular}

Source: SPSS Result, 2019

As shown in Table 3, an item-total correlation test is performed to check if any item in the set of tests is inconsistent with the averaged behaviour of the others, and thus can be discarded. A reliability analysis was carried out on the variables of the study values scale comprising three (3) items. Cronbach's Alpha showed the questionnaire to reach acceptable reliability, $\alpha=0.854$. All items appeared to be worthy of retention, resulting in a decrease in the alpha if deleted. There is no exception to this in all

\section{Models Specification}

Guided by the functional relationship between the variables of the study, the model is expressed in implicit and explicit function as shown below:

$\mathrm{PEF}=f(\mathrm{STA}, \mathrm{STH})$

Where,

$\mathrm{PEF}=$ Students' Performance STA $=$ Student Attitude

STH = Study Habit

In explicit form, the functional relationship between the variables of the study can be shown below:

$\mathrm{PEF}=\mathrm{b}_{0}+\mathrm{b}_{1} \mathrm{STA}+\mathrm{b}_{2} \mathrm{STH}+\mathrm{Ut}_{\mathrm{t}} \quad-\quad(7)$

Where,

b0 $=$ Regression constant

b1 - b2 = coefficients of independent variables. 
Ut is the error term

\section{A priori expectations}

$\left(\boldsymbol{X}_{\mathbf{1}}\right)=$ Student Attitude; a priori expectation is \pm the variables of the study as none of the items if deleted will improve the overall Cronbach alpha statistics. As such, none of the variables was removed. A correlation value less than 0.2 or 0.3 indicates that the corresponding item does not correlate very well with the scale overall and, thus, it may be dropped. $\left(\boldsymbol{X}_{\mathbf{2}}\right)=$ Study Habit: a priori expectation is \pm The Ordinary Least Square regression (OLS) analysis was used to assess the nature and degree of relationship between the dependent variable and a set of independent or predictor variables. However, the probability value o the estimates will be used to test the 2 hypotheses of this study.

Decision rule: The following decision rules were adopted for accepting or rejecting hypotheses: If the probability value of $b_{i}[p(\mathrm{bi})>$ critical value] we accept the null hypothesis, that is, we accept that the estimate bi is not statistically significant at the $5 \%$ level of significance. If the probability value of $b_{i}[p(\mathrm{bi})<$ critical value] we reject the null hypothesis, in other words, that is, we accept that the estimate b1 is statistically significant at the $5 \%$ level of significance

\subsection{RESULTS AND DISCUSSION}

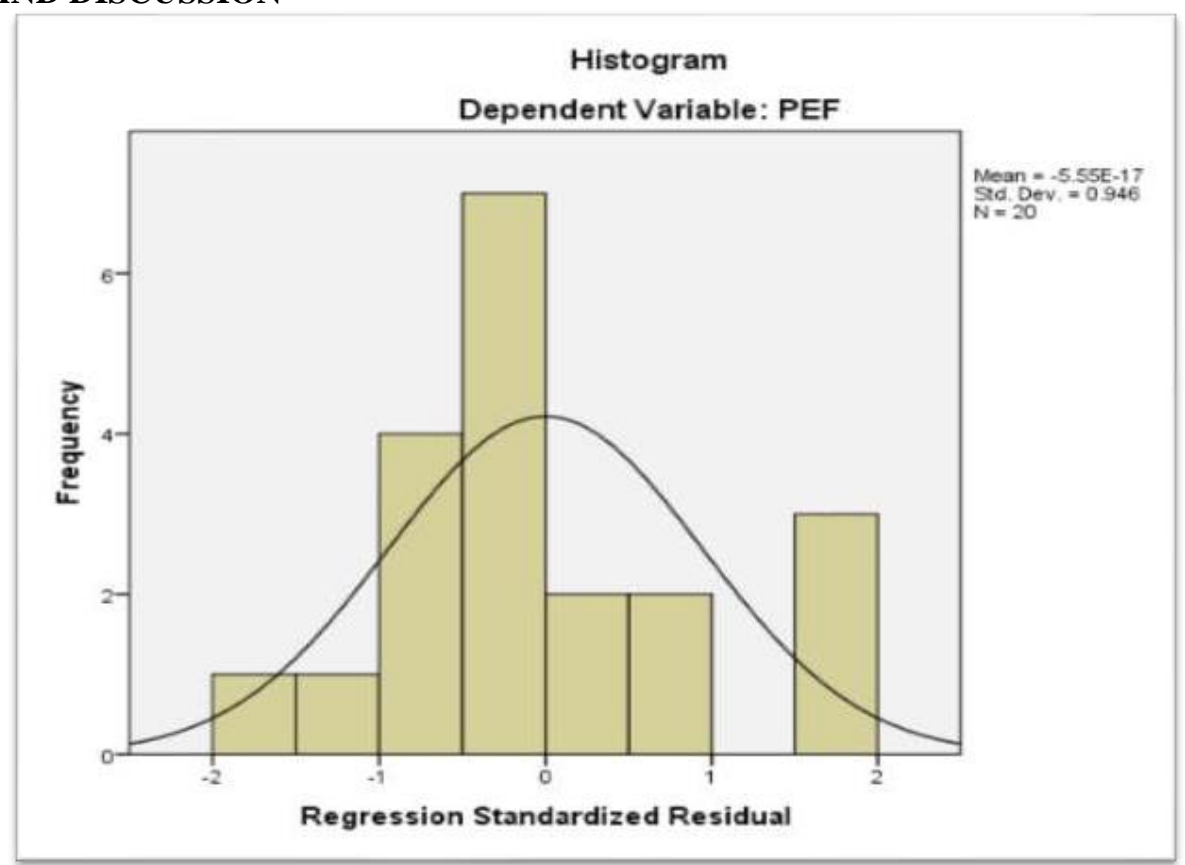

Figure 1: Regression Standardized Residual

Figure 1 above shows a histogram of the residuals with a normal curve superimposed. The residuals look close to normal, implying a normal distribution of data. Here is a plot of the residuals versus predicted dependent variable of students performance (PEF). The pattern shown above indicates no problems with the assumption that the residuals are normally distributed at each level of the dependent variable and constant in variance across levels of Y.

Table 4: Statistical Significance of the model

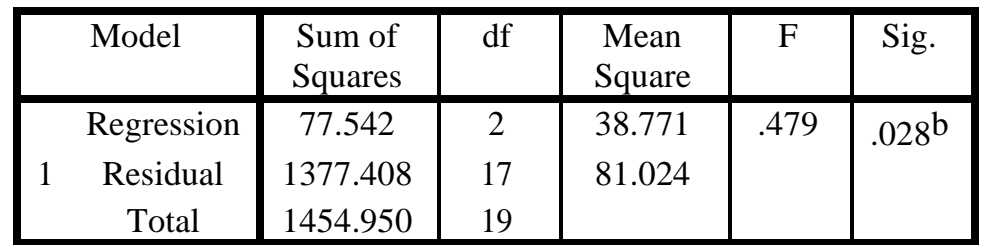

a. Dependent Variable: PEF

b. Predictors: (Constant), STH, STA

Source: SPSS 20.0 Result Output, 2019

The result of the statistical significance of the model is presented in Table 13. The F- ratio in the ANOVA table above tests whether the overall regression model is a good fit for the data. The table shows that the independent variables statistically significantly predicts the dependent variable $\mathrm{F}(2,17)=0.479, p=0.028^{\mathrm{b}}$ (i.e., the regression model is a good fit of the data). 
Table 5: Model summary

Model Summaryb

\begin{tabular}{|c|c|c|c|c|c|}
\hline Model & $\mathrm{R}$ & $\mathrm{R}$ Square & $\begin{array}{c}\text { Adjusted R } \\
\text { Square }\end{array}$ & $\begin{array}{c}\text { Std. Error of the } \\
\text { Estimate }\end{array}$ & Durbin-Watson \\
\hline 1 & $.823^{\mathrm{a}}$ & .705 & .581 & 9.00133 & 2.064 \\
\hline
\end{tabular}

a. Predictors: (Constant), STH, STA

b. Dependent Variable: PEF

Source: SPSS 20.0 Result Output, 2019

Table 5 shows the model summary. The coefficient of determination $\mathrm{R}^{2}$ for the study is 0.705 or $70.5 \%$. This indicates that $70.5 \%$ of the variations in the model can be explained by the explanatory variables of the model while 29.5 of the variation can be attributed to unexplained variation captured by the stochastic term. The Adjusted $\mathrm{R}$ Square and $\mathrm{R}^{2}$ show a negligible penalty $(58.1 \%)$ for the explanatory variables introduced by the researcher. The Durbin Watson statistics is 2.064 shows that there is a minimal degree of negative autocorrelation in the model of the study; hence the estimates of the model can be used for prediction.

Table 6: Regression coefficients

\begin{tabular}{|c|c|c|c|c|c|c|c|}
\hline \multicolumn{8}{|c|}{ Coefficients $^{a}$} \\
\hline \multirow[t]{2}{*}{ Model } & \multicolumn{2}{|c|}{$\begin{array}{l}\text { hstandardized } \\
\text { Coefficients }\end{array}$} & \multirow{2}{*}{$\begin{array}{l}\text { ptandardiz } \\
\text { ed } \\
\text { Coefficien } \\
\text { ts }\end{array}$} & \multirow[t]{2}{*}{$\mathrm{t}$} & \multirow[t]{2}{*}{ Sig. } & \multicolumn{2}{|c|}{$\begin{array}{l}\text { Collinearity } \\
\text { Statistics }\end{array}$} \\
\hline & B & $\begin{array}{l}\text { Std. } \\
\text { Error }\end{array}$ & & & & \begin{tabular}{|r|} 
Toleran \\
ce
\end{tabular} & VIF \\
\hline (Constant) & .550 & .429 & & .664 & .002 & & \\
\hline $1 \quad$ STA & .160 & .187 & .208 & .856 & .039 & .943 & 1.060 \\
\hline STH & -.068 & .266 & -.062 & -.256 & .801 & .943 & 1.060 \\
\hline
\end{tabular}

a. Dependent Variable: PEF

Source: SPSS 20.0 Result Output, 2019

As shown by the result of the multiple regression, study attitude has a positive effect on Student Attitude (STA) and Student Performance (PEF) and the relationship is statistically significant $(p<0.05)$ and in line with a priori expectation. This means that a unit increases in on Student Attitude (STA) will result to a corresponding increase in the Student Performance (PEF) by margin of $20.8 \%$. Using the probability value of the estimate, $p$ (b1) < critical value at 0.05 confidence level. Thus, we reject the null hypothesis. That is, we accept that the estimate b1 is statistically significant at the $5 \%$ level of significance. This implies Student attitude has a significant effect on the performance in selected secondary schools in Makurdi Metropolis.

This finding is in line with that of Jones and Ruch (1928) and Crawford (1929) who conducted investigations into the relationship between study time and academic performance. Their findings were based upon a study timetable covering the period of 1 week, and their results were low. Between them, these investigators found correlations between 0.04 and 0.11 . This implies that high correlations emerged only when students were asked to assess the amount of time they spent in study over an extensive period of about a year. Thus, meaning that the assessment of students' attitude of study time have positive implications to their performance.

Study habit (STH) was negatively related to Student Performance in selected Secondary Schools in Makurdi Metropolis $(\mathrm{PEF})$ and the relationship is not statistically significant $(p>0.05)$ and in line with a priori expectation. This means that a unit increases in Study Habit (STH) will result to a corresponding decrease in Student Performance in selected Secondary Schools in Makurdi Metropolis (PEF) by margin of

$6.2 \%$. Using the probability value of the estimate, $p\left(b_{2}\right)>$ critical value at 0.05 confidence level. Thus, we accept the null hypothesis. That is, we accept that the estimate b2 is not statistically significant at the $5 \%$ level of significance. This implies that Study habit has no significant effect on the performance in selected secondary schools in Makurdi Metropolis. This finding is also in line with that of Marc (2011) who explains that students with learning problems, however, may still have generally inefficient and ineffective study habits and skills. He observes that good study habits are essential to educational success; as they contribute to a successful academic future. Good study habits lead to good grades while good grades lead to admissions to better colleges and universities. The negative none statistically significant effect of study habit of on student's performance in the result of this present study could be as a result of the choice of wrong study habit.

The result of this study also is contrary to the finding of Onwuegbuzie (2001) who conducted a study to find out the relationship between academic success and study habit. The study reported positive relationship between the two variables (academic success and study habit). In like manner, the National Assessment of Educational Progress (1994) conducted a study to ascertain the relationship between study habits and the academic performance of the students. Findings of the study revealed a positive correlation between study habit and academic achievement (Omotere, 2011). 
According to Adeninyi (2011), good study habits allow students to study independently at home and aspire for higher educational career. The formation of good study habits in secondary school level further serves as the basis for students' performance in external examinations such as WAEC, NECO and JAMB, he submits. In the view of Agba (2013), unserious students do study anyhow without specific techniques and he submits that such students are most likely to perform below average. Thus, he concludes that good study habits help students to- attend classes very often and do so on time. It also helps them to submit their assignment on time, read or prepare very well for tests and exams, take down notes and develop the points independently, ask relevant questions in class; thereby having good grades at the end of the term or semester.

\subsection{CONCLUSION AND RECOMMENDATIONS}

\section{Conclusions}

This study investigated attitude, study habit and its impact on students' academic performance in selected secondary schools in Makurdi Metropolis. The study found that educators vary in their opinion of the nature of good study habits and proper school attitudes. Evidence for this is demonstrated both in published works and in the wide differences that occur in the amount of homework assigned. Those who believe in home study and proper study habits are apt to assign heavy workloads. Other educators are more likely to favor proper motivation toward school as the key to effective learning.

These individuals are apt to feel that study techniques are of decidedly secondary importance. This controversy is probably due to the absence until recently of a satisfactory research instrument of attitude and study habit. Based on the findings of the study, the researcher concludes that student's attitude within the study area has negative effect on performance.

The study also concludes that study attitude had a positive effect on secondary school students' academic performance. This study showed that student attitude has a significant effect on students' performance and academic achievement in the selected secondary schools in Makurdi Metropolis.

\section{Recommendations}

The following recommendations are made based on the results of the study:

1. Mathematics teachers in Nigerian secondary schools are also called upon to always make Mathematics classes very interesting and engaging for students. By so doing, the attitude, good study habits and performances of the students in Mathematics will no doubt improve.

2 In line with the findings of the study, the researcher recommended that teachers and school guidance counselors should collaboratively guide students on how to develop good study habits, thereby enhancing their academic success. The negative effect of study habit on students' performance in the study area implies that the present study provides merit for comprehensive academic interventions to improve the study habits and attitudes of the students so as to improve their academic performance.

\section{REFERENCES}

[1].Acido, M. (2010). High School Students Reasoning Skills and Their Study Habits and Attitude Towards Learning Alipats: A Journal of Basic Education, 4, 108-117. Retrieved at http://journals.upd.edu.ph/index.php/ ali/article/viewfile/1769/1685

[2].Adeninyi, V. (2011). Studying to Pass: Implication for Students. Lagos: Macmillan, pp. 76-78.

[3].Agba, R. (2013). Why Students must Develop Study Habits. Calabar: Rixmas Publishing Company.

[4].Ansari, Z. A. (1994). Study habits and attitudes of students: development and validation of questionnaire measures. Islamabad: National institute of psychology press, pp. 96- 99.

[5].Awang, M. and Sinnadurai, (2010). A Study on the Development of Strategic Tools in Study Orientation Skills towards Achieving. Journal of Language Teaching and Research, 2(1): 60-67.

[6].Azikiwe, U. (1998). Study approaches of university students. WCCI region II forum, 2. Lagos, 106-114.

[7].Bridgeman, B., McCamley-Jenkins, L. and Ervin, N. (2000). Predictions of freshman grade point average from the revised and reentered SAT I: Reasoning Test: Impact on Admitted Class Composition and Quality(College Board Rep. No. 2001-3). New York: College Entrance Examination Board.

[8].Charnley, K. (2006). Motivation for the Lazy high school student. Retrieved July, 23 2019 http://www.articlebeam

[9].Charles-Ogan, G. and Alamina, J. (2014) examined Differential Students' Study Habit and Performance in Mathematics. Journal of Education and Practice. Available Online @ www.iiste.org, Vol.5, No.35, 2014

[10]. Cooper, B. and Foy, J. M. (1969). Students' study habits, attitudes and academic attainment. Universal Quarterly Journal, 24, 203-212.

[11]. Crawford, A. B. (1929). Incentives to Study. (New Haven: Yale University Press).

[12]. Crede, M., and Kuncel, N. (2008). Study Habits Meta-Analysis. Perspectives on Psychological Science, 3(6):425453.

[13]. Fisher, L. A. and Cotsonas, N. J. (1965). A time study of student activities. Journal of Education, 40, $125-132$.

[14]. Gettinger, M., and Seibert, J.K. (2002). Contributions of study skills to academic competence. School Psychology Review, 31, 350-365.

[15]. Good, T. L. (1998). Pygmalion grows up: Studies in the expectation communication process. New York: Longman, pp.87-91.

[16]. Grace, F. (2013). Would Group Study Improve Your Grades? Retrieved from www.about.com. 11/3/2016.

[17]. Hackbarth, S. L. (1997). Reflections on confluent education as discipline- based inquiry. Paper presented at the 
annual meeting of the American Educational Research Association, Chicago.

[18]. Hair, J. F., Anderson, R. E., Tatham, R. L. and Black, W. (1995). Multivariate Data Analysis, (5th edn). Pearson: United States, pp.48-53

[19]. Harper, T. and Row, A. (2009). Effective Study Habits. Retrieved fromwww.arbeitsblaetter.com.12/3/2016.

[20]. Hurlburt, G., Kroeker, R., and Gade, E., (1991). Study Orientation, Persistence and Retention of Native Students: Implications for Confluent Education, Journal of American Indian Education, 30(3):56-67.

[21]. Husain A (2000). Developing Study Habits. Wikipedia, the free encyclopedia, pp. 25-26.

[22]. Hussain, A. (2006). Effect of Guidance Services on Study Attitudes, Study Habits and Academic Achievement of Secondary School Students, Bulletin of Education and Research, 28(1):35-45 John, M. (2010). Students Study Habits and Styles. Retrieved fromwww.worldwidelearn.com. 12/3/2016.

[23]. Jones, L. and Ruch, G. M. (1928). Achievement as affected by total time studied. 27th Yearbook of the National Society for the Study of Education, 11, 131-136.

[24]. Katelyn, F. (2013). College Study Habits News. Retrieved fromwww.studymode.com/essays. 12/3/2016.

[25]. Kelli, K. (2009). Developing Good Study Habits. Retrieved from monster.com. media/ads. 11/3/2016.

[26]. Lock, C. (1981). Study skills (Indiana, Kappa Delta Publication, West Lafayette 1(5) 7 - 26)

[27]. Mackeracher, D. (1996). Making sense of Adult Learning Toronto: Culture Concepts, Inc

[28]. Marc K (2011), The Importance of Good Study Habits. Retrieved fromwww.answer.com. 12/3/2016.

[29]. Mark, A. and Howard, C. (2009). How to Study. Psychological Science Review, 20(4):516-522.

[30]. National Assessment of Educational Progress (1994). U.S. History Framework. Washington, DC: Assessment Governing Board, U.S. Department of Education, Government Printing Office, pp. 65-76.

[31]. Nikki, K. (2013). Common Bad Study Habits. Retrieved from www.newa4j ax.com2/4/2016.

[32]. Nneji, L. M. (2002). Study habits of Nigerian university students. Nigerian educational research and development council, Abuja, Nigeria.

[33]. Ogunyemi, A. and Hassan, E. (2011). Academic Self-Efficacy, Study Habit and Attitude in School-Based Assessment, African Journal for the Study of Educational Issues, 4(21):20-21.

[34]. Oluche, R. O. (1998). Learning and Teaching of Senior Secondary School, Mathematics in Anambra State (Unpublished Seminar Paper).

[35]. Omotere, T. (2011). The effects of study habit on the academic performance of students. Ogun: Ego Booster Books, pp. 62-79.

[36]. Sorensen, V. (2006). Motivating middle school mathematics students. Onwuegbuzie, U. (2001). Correlation between Study Habit and Students' Academic Success. Jos Journal of Education, 2(1):27.

[37]. Oyedeji, O. A. (2016). Perseverance, Study habit and self concept as predictors of students' performance in secondary school mathematics in Nigeria. Journal of Leadership and Instruction. Vol 3, Issue 7

[38]. Ranjana, C., Kumar D, D. (2012) Influence of Attitude Towards Mathematics and Study Habit on the Achievement in Mathematics at the secondary stage. International Journal of Engineering Research and Applications. Available @ www.ijera.com 2(6), pp.192-196

[39]. Riaz, A. Kiran, A., Malik, N. (2002). Relationship of study habits with educational achievements. International Journal of Agriculture and Biology, 4(3):370-371. American Educational Research Journal, 45(3):767-795. 